\title{
LEWATIT SYBRON IONAC SR 7 VE LEWATIT MP 600 REÇINNELERI İLE SULU ÇÖZELTİLERDEN Cr (VI) GIDERIMII: DENGE VE MODELLEME ÇALIŞMASI
}

\author{
1Deniz ÜMMETOĞLU (iD) , ${ }^{2}$ Erol PEHLIVAN (iD) \\ Konya Technical University, Engineering and Natural Sciences Faculty, Chemical Engineering Department, \\ Konya, TURKEY \\ ${ }^{1}$ dummetoglu@ktun.edu.tr, ${ }^{2}$ epehlivan@ktun.edu.tr
}

\section{Geliş/Received: 16.09.2021; Kabul/Accepted in Revised Form: 26.11.2021)}

ÖZ: Bu araştırmada, Lewatit MP 600 ve Lewatit Sybron Ionac SR 7 reçineleri kullanılarak Cr (VI)'nın sulu çözeltilerden giderilmesi amaçlanmıştır. Bu reçineler, $\mathrm{Cr}$ (VI)'nın sudan uzaklaştırılması için ideal bir tutucudur. $\mathrm{Cr}(\mathrm{VI})$ giderimi için temas süresi, başlangıç $\mathrm{Cr}(\mathrm{VI})$ konsantrasyonu, $\mathrm{pH}$ ve reçine miktarı gibi belirli parametrelerin denge çalışmaları üzerine etkisi incelenmiştir. Kısa sürede dengeye ulaşılarak sulu ortamdan hızlı Cr (VI) giderimi, reçinelerin Cr (VI)'yı tutma etkinliğinin yüksek olduğunu göstermiştir. Lewatit MP 600 ve Lewatit SR 7 reçinelerinin, Cr (VI) iyonlarını tutmasından önce ve sonrası için Fourier Dönüşümlü Kızılötesi Spektroskopisi (FT-IR) ile reçinelerin karakterizasyonu ve Taramalı Elektron Mikroskobu (SEM) ile yüzey morfolojisi incelenmiştir. Cr (VI)'nın sulu ortamdan giderim miktarının bulunması ve reçinelerin kapasite tayini için dengede kalan $\mathrm{Cr}$ (VI) konsantrasyonuna karşı, reçine tarafından tutulan Cr (VI) grafikleri çizilmiştir. Grafiklere Langmuir, Freundlich, Dubinin-Raduskevich (D-R), Scatchard adsorpsiyon izoterm modelleri uygulanarak reçinelerin kapasite tayini yapılmıştır. Kullanılan reçineler için Langmuir izoterm modelinin $\mathrm{Cr}(\mathrm{VI})$ giderimi için daha uygun olduğu sonucuna varılmıştır. Yalanc1-ikinci-derece kinetik model, yalanc1-birinci-derece kinetik modele göre $\mathrm{Cr}$ (VI) giderimi için daha uygun olmuştur. Yapılan deneylerden, bu ticari reçinelerin sulu çözeltilerden $\mathrm{Cr}$ (VI) uzaklaştırılması için uygun reçineler olduğu görülür ve arıtma tesislerinde kullanılması önerilir.

Anahtar Kelimeler: Reçine, Cr (VI), Denge, Kinetik, Izoterm

\section{Cr (VI) Removal from Aqueous Solutions by Lewatit Sybron Ionac SR 7 and Lewatit MP 600 Resins: Equilibrium and Modelling Study}

\begin{abstract}
In this research, it was aimed to remove $\mathrm{Cr}$ (VI) from aqueous solutions by using Lewatit MP 600 and Lewatit Sybron Ionac SR 7 resins. These resins are an ideal scavenger for the removal of $\mathrm{Cr}$ (VI) from water. For Cr (VI) removal, the effects of certain parameters such as contact time, initial Cr (VI) concentration, $\mathrm{pH}$ and resin content on equilibrium studies were investigated. The rapid removal of $\mathrm{Cr}$ (VI) from the aqueous medium by reaching equilibrium in a short time showed that the $\mathrm{Cr}$ (VI) retention efficiency of the resins was high. Characterization of resins by Fourier Transform Infrared Spectroscopy (FT-IR) and surface morphology by Scanning Electron Microscope (SEM) were investigated before and after Lewatit MP 600 and Lewatit SR 7 resins adsorb Cr (VI) ions. To determine the amount of Cr (VI) removal from the aqueous medium, in other words, the capacity determination of the resins, the $\mathrm{Cr}$ (VI) values retained by the resin against the equilibrium $\mathrm{Cr}$ (VI) concentration were plotted. The capacity of the resins was determined by applying Langmuir, Freundlich, Dubinin-Raduskevich (D-R), Scatchard adsorption isoterm models to the graphs. It was concluded that Langmuir isotherm model is more suitable for $\mathrm{Cr}(\mathrm{VI})$ removal for the resins used. The pseudo-second-order kinetic model was more suitable for $\mathrm{Cr}$ (VI) removal than the pseudo-first-order kinetic model. From the experiments, it is seen that these
\end{abstract}


commercial resins are suitable resins for the removal of $\mathrm{Cr}$ (VI) from aqueous solutions and are recommended for use in treatment plants.

Keywords: Resin, Cr (VI), Equilibrium, Kinetics, Isoterm

\section{GİRIŞ (INTRODUCTION)}

$\mathrm{Su}$, canlı yaşamının sürdürülebilir olması için gerekli vazgeçilmez bir yaşam kaynağıdır. Gelişen teknolojinin yaşamımıza getirdiği konfor yanında, bu gelişmenin doğaya ve çevreye verdiği zararın boyutu her geçen gün hızla artmaktadır. Temiz su kaynaklarının azalması hatta yakın gelecekte tükenmesi söz konusu olduğundan atık suların geri kazanım prosesleri geliştirilmektedir. Ağır metaller, atık sulara bırakılan en önemli kirletici madde sınıflarından biridir. Toksik ve kansorojen etkileri olduğu gibi, canlı organizmada biyobirikime yol açtığından oldukça tehlikeli maddelerdir. Gelişmekte olan ülkelerde ortaya çıkan hastalıkların çoğu içme suyundan kaynaklanmaktadır ve toksik maddeler ve bakteriler bunların içerisinde oldukça önemlidir (Ashbolt, 2004). Dünyada toksik metallerin sebep olduğu su kirliliği sorunu oldukça yaygınlaşmıştır ve temel sorun haline gelmiştir. Genel olarak; ağır metaller, sentetik boyalar, pestisitler, farmasötikler su kirlilğine yol açan ekolojik gruplardır (Parlayıcı ve Pehlivan, 2020). Civa, krom, kurşun, arsenik ve kadminyum gibi ağır metaller, zihinsel ve nörolojik yapıyı bozarak çeşitli hastalıklara sebep olurlar (Adam ve ark., 2018).

\section{Cr (VI) ve Özellikleri (Cr (VI) and Properties)}

Krom d grubu bir geçiş elementidir ve periyodik cetvelin 6 . bloğunun ilk üyesidir. $-2,-1,0,+1,+2,+3$ ve +4 gibi çeşitli oksidasyon durumlarını ve çok çeşitli kimyasal ve fiziksel özellikler gösterir. Oksidasyon durumlarına göre; asidik, alkali ve amfoterik oksitler oluşturabilir. En kararlı krom oksidasyon durumları; $\mathrm{Cr}$ (III) ve $\mathrm{Cr}(\mathrm{VI})$ olduğunda oluşur. Sudaki $\mathrm{Cr}(\mathrm{VI})$ türlerinin çoğu dikromat $\left(\mathrm{Cr}_{2} \mathrm{O}_{7^{2}}\right)$, kromat $\left(\mathrm{CrO}_{4}{ }^{2-}\right)$, kromik asit $\left(\mathrm{H}_{2} \mathrm{CrO}_{4}\right)$ ve hidrojen kromat $\left(\mathrm{HCrO}_{4}^{-}\right)^{\prime}$ tır. $\mathrm{Cr}(\mathrm{III})$ türleri ise çoğunlukla $\mathrm{Cr}_{3}{ }^{+}, \mathrm{Cr}(\mathrm{OH})^{2+}, \mathrm{CrO}^{+}$, $\mathrm{HCrO}_{2}$ ve $\mathrm{CrO}_{2}{ }^{\prime}$ dir. Krom metal ve çelik gri renktedir. Metalik bir parlaklığa sahiptir. Sert ve kırılgandır, kararmaya direnir. Kaynama noktaları sırasıyla $1907^{\circ} \mathrm{C}$ ve $2671^{\circ} \mathrm{C}^{\prime}$ dir (Pradhan ve ark., 2017). Pek çok krom bileşiği nispeten suda çözünmezdir. Cr (III) bileşikleri suda çözünmez. Krom (III) oksit ve krom (III) hidroksit, suda çözünür tek bileşiklerdir. Krom (VI) oksit, suda mükemmel şekilde çözünür. İçme sularında izin verilen maksimum sınır Cr (III) için $5 \mathrm{mg} / \mathrm{L}$ iken $\mathrm{Cr}$ (VI) için 0,05 mg/L'dir (Ali ve ark., 2015). Bu nedenle, $\mathrm{Cr}(\mathrm{VI})$ 'nın atık sulardan uzaklaştırılması, aktif bir araştırma ve geliştirme alanıdır. $\mathrm{Cr}(\mathrm{VI})^{\prime} \mathrm{y}$ I sudan uzaklaştırmak için kullanılan diğer yöntemler arasında, sulu ortamdan metal iyonlarını uzaklaştırmak için anyonik iyon değişim reçinesine dayalı yöntemler, metaller için reçinelerin daha iyi seçiciliği ve daha az çamur üretimi nedeniyle, diğer tekniklere göre genellikle daha avantajlıdır (Ali ve ark., 2015).

Yüksek miktarda Cr (VI), karaciğer ve böbrek yetmezliğine sebep olur. Akciğerlere zarar vererek astım gibi solunum yolu rahatsızlarına yol açar. Anemi, deri alerjisi gibi rahatsızlıklara ve mide kanseri başta olmak üzere çeşitli kanser hastalıklarına neden olur (Economou-Eliopoulos ve ark., 2012). Bunların yanı sıra Cr (VI) ağır metali; mide bulantısı, ishal, dermatit, iç kanama ve solunum problemleri oluşturur. Deriyle temas etmesi halinde sistemik zehirlenmeye, ciddi yanıklara ve mevcut yara veya kesiklerin iyileşmesini engeller. Eğer tedavi edilmezse ciddi alerjik dermatiteye sebebiyet verir. Göze temas etmesi halinde, gözde kalıcı hasarlara neden olabilir (Mohan ve ark., 2011). Cr (III) eser miktarlarda canlılar için önemli bir mikro besin kaynağıdır (Gandhi ve ark., 2010). Cr (III) iyonları canlı yaşamı için gereklidir ve $\mathrm{Cr}$ (VI) iyonu ile kıyaslandığında toksisitesi oldukça düşüktür.

Son yıllarda hızla büyüme gösteren endüstri sektörünün, özellikle metal kaplama, elektronik cihazlar, madencilik, pigmentasyon gibi sektörlerin atık sularında $\mathrm{Cr}$ (VI) konsantrasyonunun artmasıyla birlikte, toksisitesi yüksek bu ağır metal iyonunun giderilmesi için birçok farklı yöntem uygulanmaktadır. Cr (VI) iyonunun belli bir konsantrasyon seviyesine düşürülerek doğaya bırakılması büyük önem arz etmektedir. 
Bununla ilgili yasal olarak sınırlamalar mevcuttur. Kimyasal çöktürme ve filtrasyon, membran teknolojileri, ters osmoz, kimyasal ve biyolojik arıtma yöntemleri, iyon değişimi, adsorpsiyon gibi farklı birçok yöntem ile atık sulardan Cr (VI) giderilmesi sağlanmaktadır. Bu kirliliğin önlenmesinde tercih edilen arıtım tekniği çoğunlukla adsorpsiyon ve iyon değiştirme teknikleridir. İyon değiştirme işlemi, diğer arıtım yöntemlerine kıyasla daha yüksek oranlarda verimlilik sağlamaktadır ve ekonomik açıdan uygundur.

İyon Değişimi Mekanizması (Ion Exchange Mechanism)

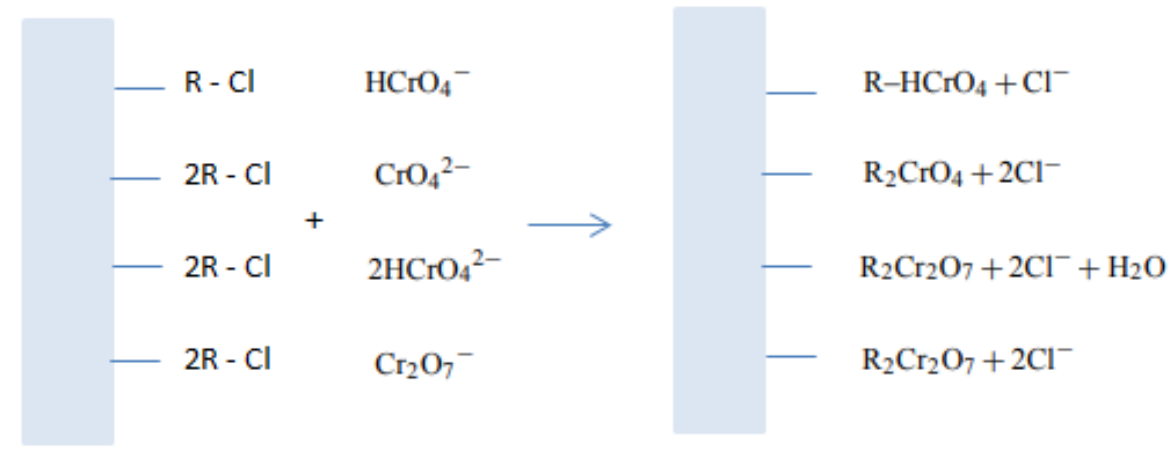

Şekil 1. İyon değişimi mekanizması.

Figure 1. Ion exchange mechanism.

İyon değişimi, elektrostatik kuvvetler yardımı ile reçine yüzeyine bağlı halde bulunan iyonların, atık suda bulunan ve giderilmesi hedeflenen farklı özellikteki iyonlar ile yer değiştirmesi işlemidir. İyon değişimi, adsorpsiyon mekanizmasının elektrostatik olduğu bir adsorpsiyon prosesidir. Şekil 1'de $\mathrm{Cl}^{-}$ iyonik formuna sahip iyon değiştirici ile $\mathrm{Cr}(\mathrm{VI})$ türleri arasındaki iyon değişimi mekanizması verilmiştir. İyon değiştirici reçine yüzeyinde bulunan yüklü fonksiyonel gruplar tarafından oluşturulan elektrostatik kuvvetler, sudaki iyonları reçine yüzeyine çekerler. Reçine yüzeyinde tutulan iyonlar, reçine matriksindeki iyonlarlarla stokiyometrik oranda yer değiştirir (Karakurt, 2019). Çözeltiden uzaklaşan her iyon, aynı yüklü diğer iyonik türlerin eşdeğer miktarıyla yer değiştirir. Adsorpsiyonda ise elektrolit veya elektrolit olmayan suda çözünen, diğer iyon türleriyle yer değiştirmeksizin tutulur.

Literatürde, Cr (VI) iyonlarının giderimi ile ilgili birçok araştırma mevcuttur (Bonilla-Petriciolet ve ark., 2017). Balan ve ark., sulu çözeltilerden Cr (VI) giderimi için jel formda iki güçlü anyonik reçine olan Purolite A-400 (stirendivinilbenzen) ve Purolite A-850 (akrilik) kullanmışlardır (Balan ve ark., 2013). Eichrom 1-X4, Lewatit M+M800 ve Lewatit A8071 reçinelerini kullanarak sulu çözeltilerden Cr (VI) iyonu giderimi incelemişlerdir (Kahraman ve Pehlivan. 2019). Bir başka çalışmada, kuvvetli anyonik iyon değiştirici Spectra/Gel IE 1X8 reçine kullanılarak atık sulardan Cr (VI) iyonları etkili bir şekilde giderilmiştir (Raşhid ve ark, 2014). Suganya ve Kumar, farklı deney şartlarında adsorban olarak kahve atığından elden edilen aktif karbonu kullanarak sulu çözeltilerden Cr (VI) iyonlarının giderilmesini araştırmışlardır (Suganya ve Kumar, 2018). Çizelge 1 incelendiğinde, bu çalışmada kullanılan reçinelerin Cr (VI) giderim kapasitelerinin, günümüzde kullanılan diğer adsorban ve reçinelerden yüksek olduğu görülmektedir. 
Çizelge 1. Literatürde Cr (VI) gideriminde kullanılan bazı adsorban, reçineler ve kapasiteleri. Table 1. Some adsorbents and resins used in $\mathrm{Cr}(V I)$ removal in the literature and their capacities.

\begin{tabular}{|c|c|c|}
\hline Adsorban & $q_{\max }(m g / g)$ & Referanslar \\
\hline Purolite A-400 & 120,55 & \multirow{2}{*}{ (Balan ve ark., 2013) } \\
\hline Purolite A- 850 & 95,82 & \\
\hline Eichrom 1-X4 & 280,25 & \multirow{3}{*}{ (Kahraman ve Pehlivan, 2019) } \\
\hline Lewatit M+ M800 & 147,67 & \\
\hline Lewatit A8071 & 163,67 & \\
\hline Spectra/Gel IE 1x8 & 173,80 & (Rashid ve ark., 2014) \\
\hline Kayısı çekirdeği aktif karbon & 55,56 & (Parlayic ve Pehlivan, 2017) \\
\hline Kahve atığ aktif karbon & 156,70 & (Suganya ve Kumar, 2018) \\
\hline Lewatit MP 600 & 227,30 & Bu çalısma \\
\hline Lewatit SR 7 & 200,00 & Bu çahşma \\
\hline
\end{tabular}

\section{MATERYAL ve YÖNTEM (MATERIAL and METHOD)}

Lewatit MP 600 ve Lewatit Sybron Ionac SR 7 Reçineleri ve Özellikleri (Lewatit MP 600 and Lewatit Sybron Ionac SR 7 Resins and Properties)

Kuvvetli anyon değiştirici olan Lewatit MP 600 ve Lewatit SR 7 reçineleri ile sulu çözeltilerden Cr (VI) giderimi çalışılmıştır. Ticari adı Lewatit olan iyon değiştirici reçineler endüstriyel atık suların arıtılmasında yaygın kullanılmaktadır (Şekil 2).
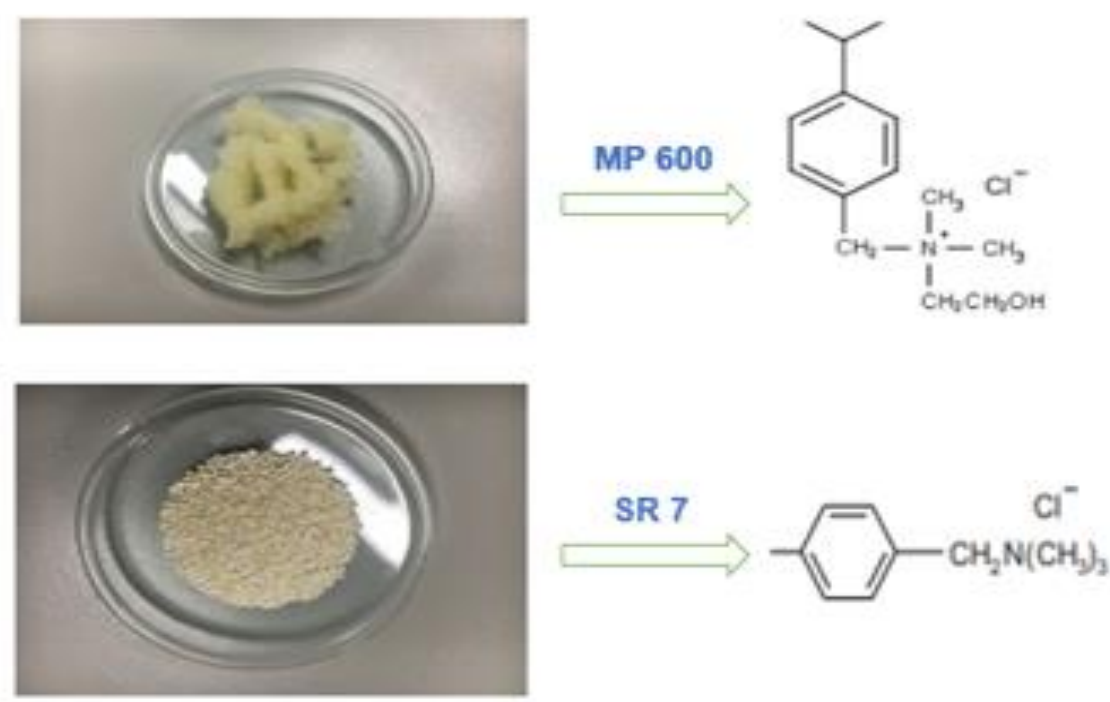

Şekil 2. Lewatit MP 600 ve Lewatit Sybron Ionac SR 7 reçineleri ve kimyasal formülleri.

Figure 2. Chemical formulations of Lewatit MP 600 and Lewatit Sybron Ionac SR 7 resins.

Polistiren matriksine sahip Lewatit SR 7 reçinesi kuaterner amonyum tip I fonksiyonel grubuna sahip makrogözenekli ve $\mathrm{Cl}^{-}$formunda kuvvetli bazik anyon değiştiricidir. Toplam kapasitesi 0,6 eq/L'ye eşittir. Ortalama tanecik boyutu $0,57-0,67 \mathrm{~mm}$, çalışma sicaklığ 1 maksimum $-80^{\circ} \mathrm{C}$ ve $\mathrm{pH}$ çalışma aralığ $0-14^{\prime}$ tür (Wawrzkiewicz ve ark., 2018). Stiren divinilbenzen matriksine sahip Lewatit MP 600 reçinesi kuaterner amonyum tip II fonksiyonel grubuna sahip kuvvetli anyonik reçinedir. Bu reçine makrogözenekli ve $\mathrm{Cl}$ iyonik formuna sahiptir. Toplam kapasitesi 1,1 eq/L'ye eşittir. Ortalama tanecik boyutu 0,55-0,65 mm, çalışma sıcaklığı maksimum $-20^{\circ} \mathrm{C}$ ve $40^{\circ} \mathrm{C}$, pH çalışma aralığ $10-14^{\prime}$ tür. Çizelge 2' de her iki reçinenin temel özellikleri verilmiştir. 
Çizelge 2. Kullanılan anyonik (bazik) iyon değiştirici reçineler ve özellikleri.

Table 2. Anionic (basic) ion exchange resins used and their properties.

\begin{tabular}{|c|c|c|c|c|c|c|}
\hline Reçine Adı & Reçine Yapısı & Reçine Özelliği & $\begin{array}{c}\text { Fonksiyonel } \\
\text { Grup }\end{array}$ & İyonik Form & $\begin{array}{c}\text { Tanecik Boyutu } \\
\text { (mm) }\end{array}$ & $\begin{array}{c}\text { Toplam } \\
\text { Kapasite } \\
\text { (min.) eq/L }\end{array}$ \\
\hline $\begin{array}{c}\text { Lewatit Monoplus } \\
\text { MP } 600\end{array}$ & $\begin{array}{c}\text { Stiren } \\
\text { divinilbenzen } \\
\text { kopolimeri }\end{array}$ & Kuvvetli bazik & $\begin{array}{c}\text { Kuaterner amin, } \\
\text { tip II }\end{array}$ & $\mathrm{Cl}$ & $0,55-0,65$ & 1,1 \\
\hline $\begin{array}{c}\text { Lewatit Sybron } \\
\text { Ionac SR 7 }\end{array}$ & $\begin{array}{c}\text { Makrogözenekli } \\
\text { çapraz bağh } \\
\text { polistiren }\end{array}$ & Kuvvetli bazik & $\begin{array}{c}\text { Kuaterner amin, } \\
\text { tip I }\end{array}$ & $\mathrm{Cl}$ & $0,57-0,67$ & 0,6 \\
\hline
\end{tabular}

\section{SEM Görüntüleri (SEM Images)}

SEM görüntüleri, Nova Nano SEM 200 (FEI Company) cihazı ile alınmıştır. Lewatit MP 600 ve Lewatit SR 7 reçinelerinin Cr (VI) giderimi öncesi ve sonrası, reçinelerin yüzey yapısını incelemek amacıyla Taramalı Elektron Mikroskobu (SEM) görüntüleri Şekil 3, Şekil 4, ve Şekil 5'de gösterilmiştir.
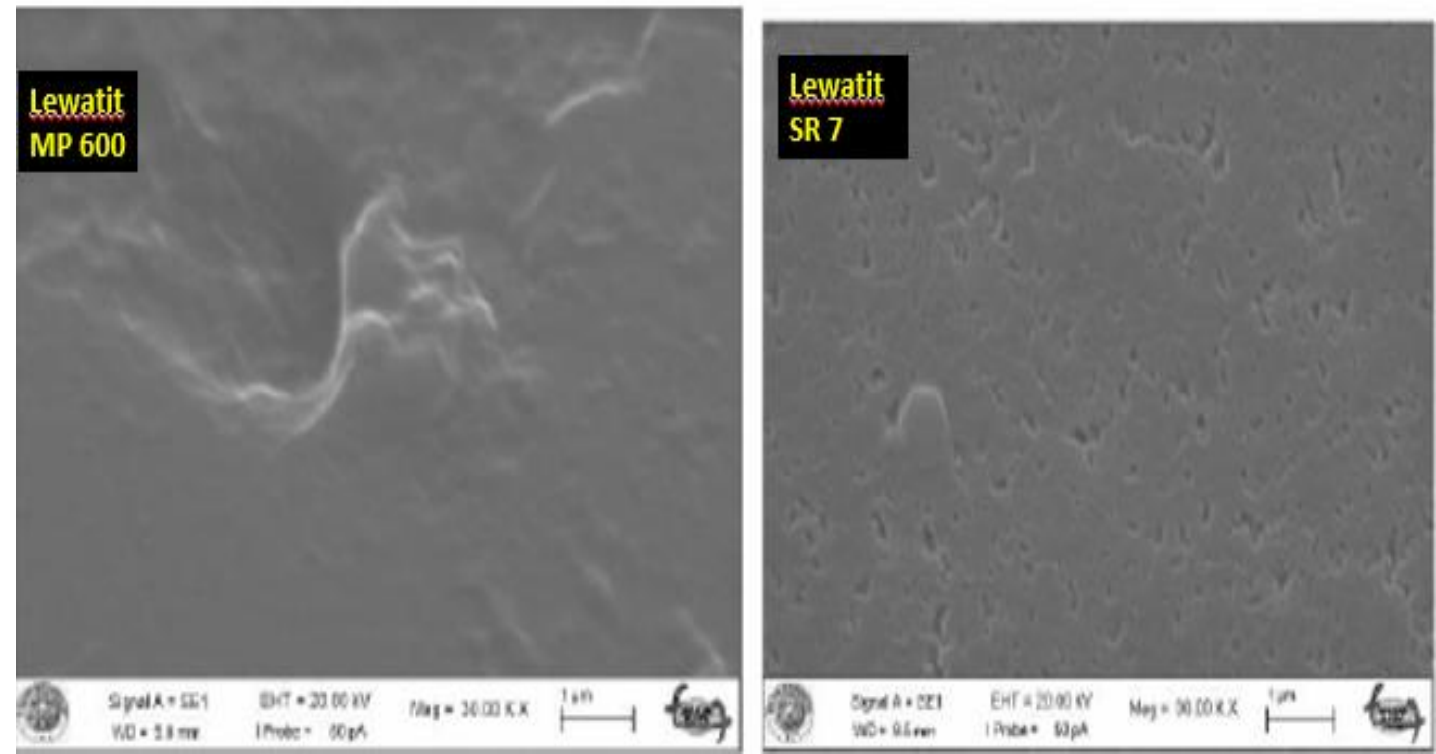

Şekil 3. Lewatit MP 600 ve Lewatit SR 7 SEM görüntüsü (Karakurt, 2018).

Figure 3. SEM images of Lewatit MP 600 and Lewatit SR 7 (Karakurt, 2018). 


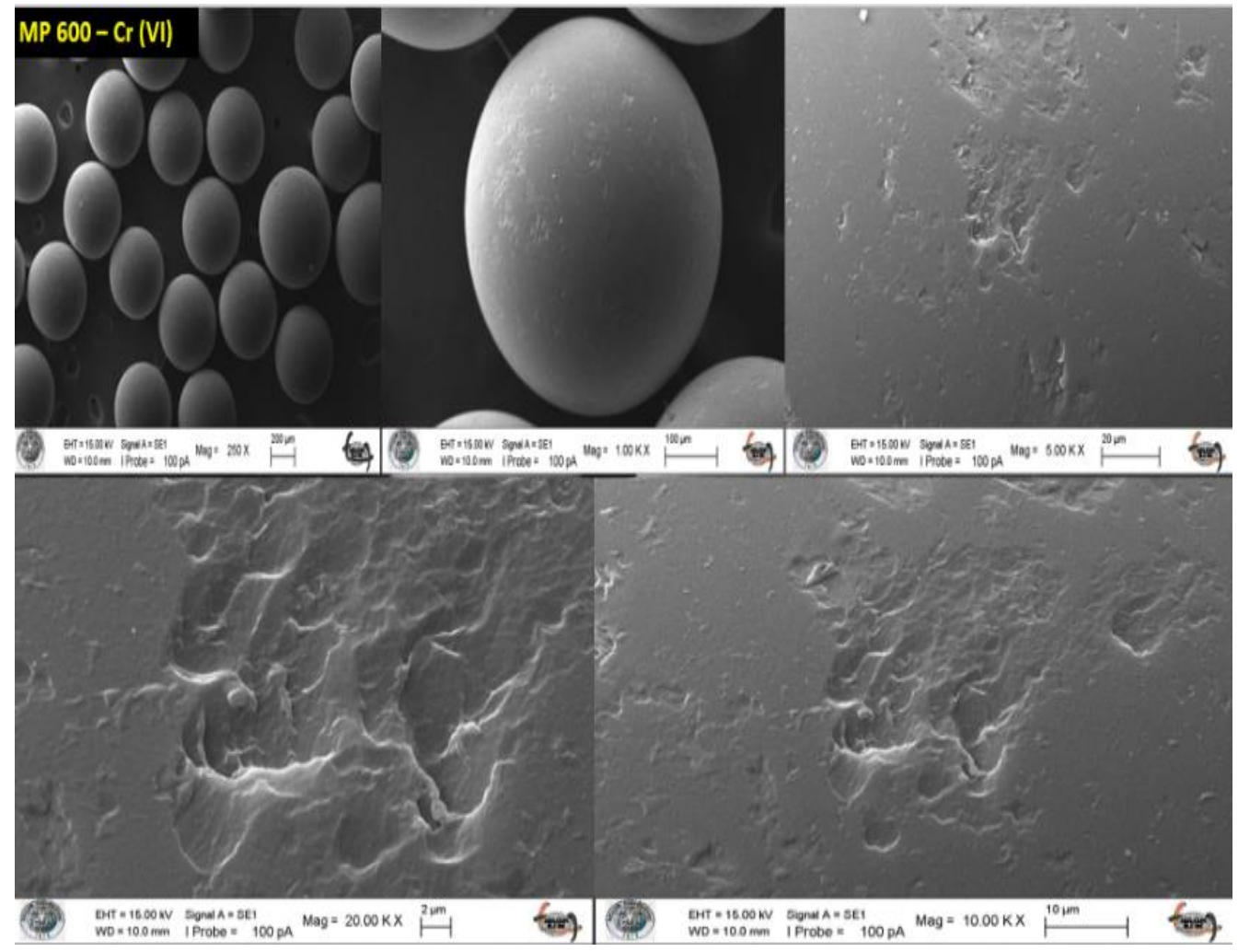

Şekil 4. Lewatit MP 600 reçinesinin Cr (VI) giderimi sonrası SEM görüntüsü. Figure 4. SEM image of Lewatit MP 600 resin after $\mathrm{Cr}(\mathrm{VI})$ removal.

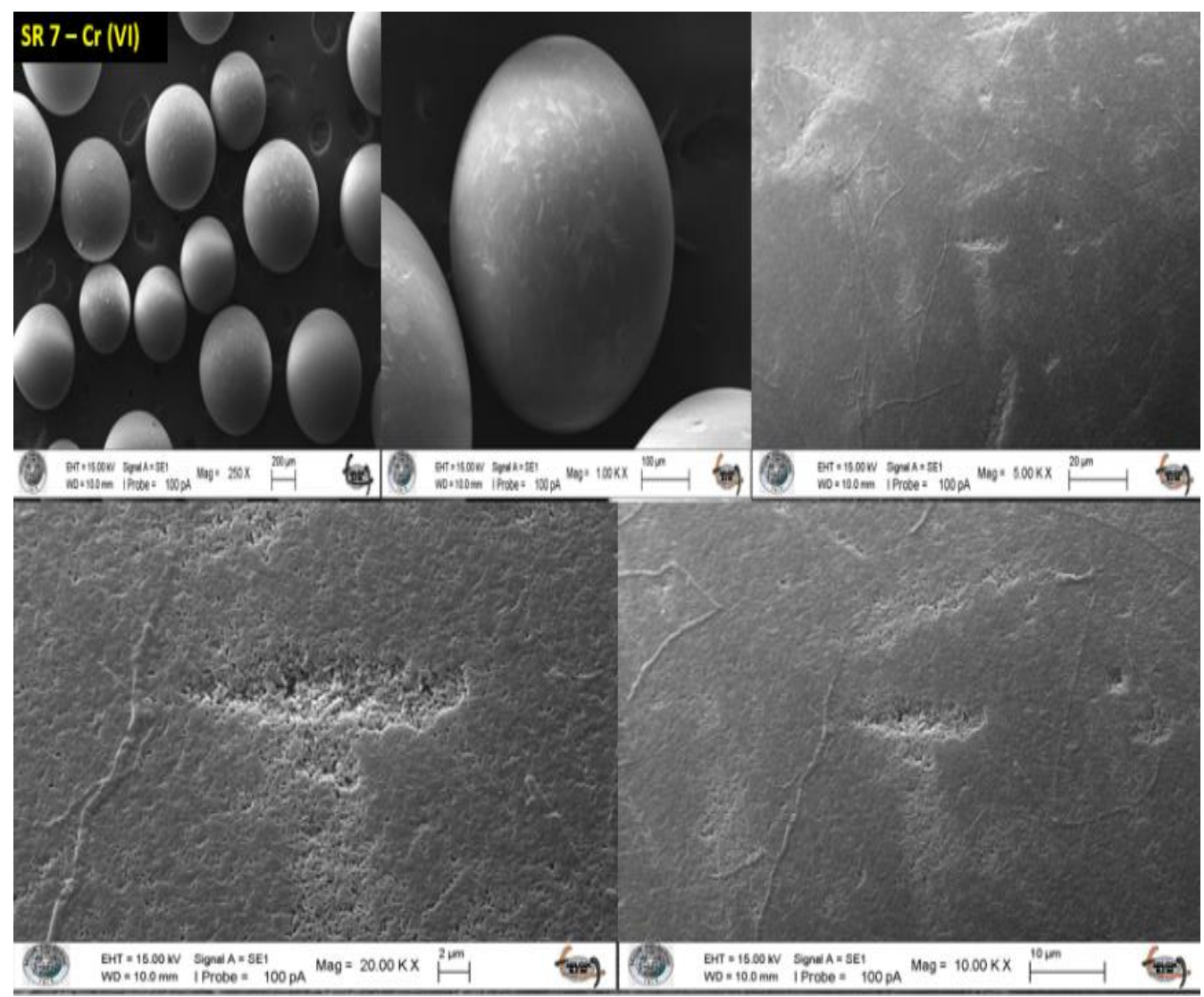

Şekil 5. Lewatit SR 7 reçinesinin Cr (VI) giderimi sonrası SEM görüntüsü.

Figure 5. SEM image of Lewatit SR 7 resin after $\mathrm{Cr}$ (VI) removal. 
Cr (VI) ile muamele edilmiş Lewatit MP 600 ve Lewatit SR 7 reçineleri ile bu reçinelerin ham hali arasındaki SEM görüntüleri incelendiğinde, $\mathrm{Cr}$ (VI) ile muamele edilen reçinelerin yüzey morfolojisinde değişiklikler gözlenmiştir. Reçinelerin orijinal helleri, daha düz bir yüzeye sahipken, Cr (VI) giderimi sonrası yüzeyde tutunan $\mathrm{Cr}(\mathrm{VI})$ iyonları nedeniyle biraz daha pürüzlü yüzeye dönüşmüştür.

\section{FT-IR Analiz Sonuçları}

FT-IR analizleri, Bruker-Platinum ATR- vertex 70 (Germany) cihazı ile yapılmıştır. Şekil 6 ve Şekil 7 incelendiğinde, $3353 \mathrm{~cm}^{-1}$ ve $3358 \mathrm{~cm}^{-1}$ de olan bantlar, yüzey üzerindeki $\mathrm{OH}$ gruplarının varlığına işaret eder. 2925-2979 $\mathrm{cm}^{-1}$ aralığında bulunan pikler, alifatik $-\mathrm{CH}_{2}$ ve $\mathrm{CH}_{3}$ gruplarında şiddetli $\mathrm{C}-\mathrm{H}$ bağlarının titreşimlerine aittir (Ngah ve Fatinathan, 2008). 1637-1478 $\mathrm{cm}^{-1}$ aralığında görülen bantlar orta dereceli $\mathrm{C}=\mathrm{C}$ bağlarından kaynaklanmaktadır. $1352 \mathrm{~cm}^{-1}$ band $\mathrm{C}-\mathrm{N}$ gruplarının gerilme titreşimlerini ve $1224 \mathrm{~cm}$ ${ }^{1}$ bandı yapıdaki C-N gerilme titreşimlerini gösterir. $954-1087 \mathrm{~cm}^{-1}$ aralığındaki bant aromatik halkalardaki C-H gerilme titreşimlerine aittir (Vedula ve Yadav, 2021).

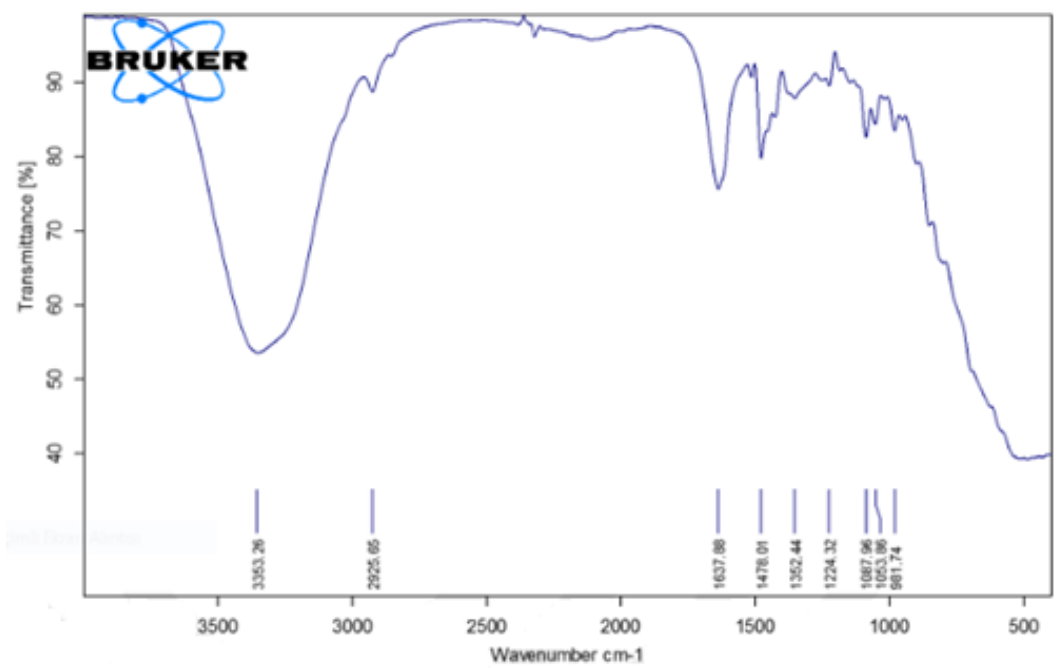

Şekil 6. Lewatit MP 600 reçinesinin FT-IR görüntüsü (Karakurt, 2018). Figure 6. FT-IR image of Lewatit MP 600 resin. (Karakurt, 2018).

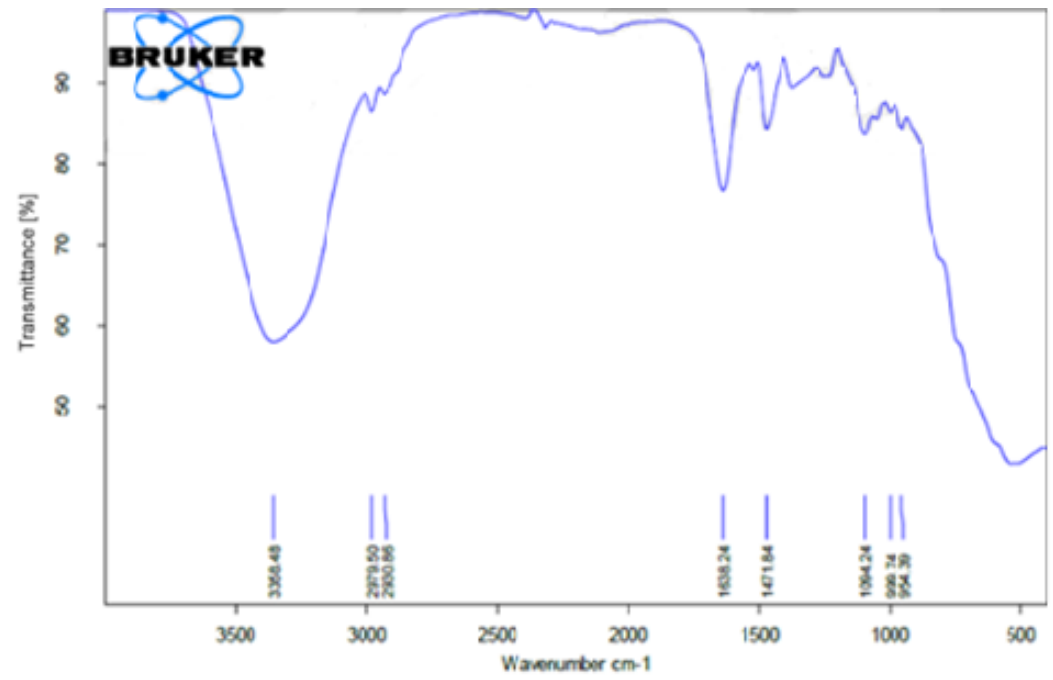

Şekil 7. Lewatit SR 7 reçinesinin FT-IR görüntüsü (Karakurt, 2018). Figure 7. FT-IR image of Lewatit SR 7 resin (Karakurt, 2018). 


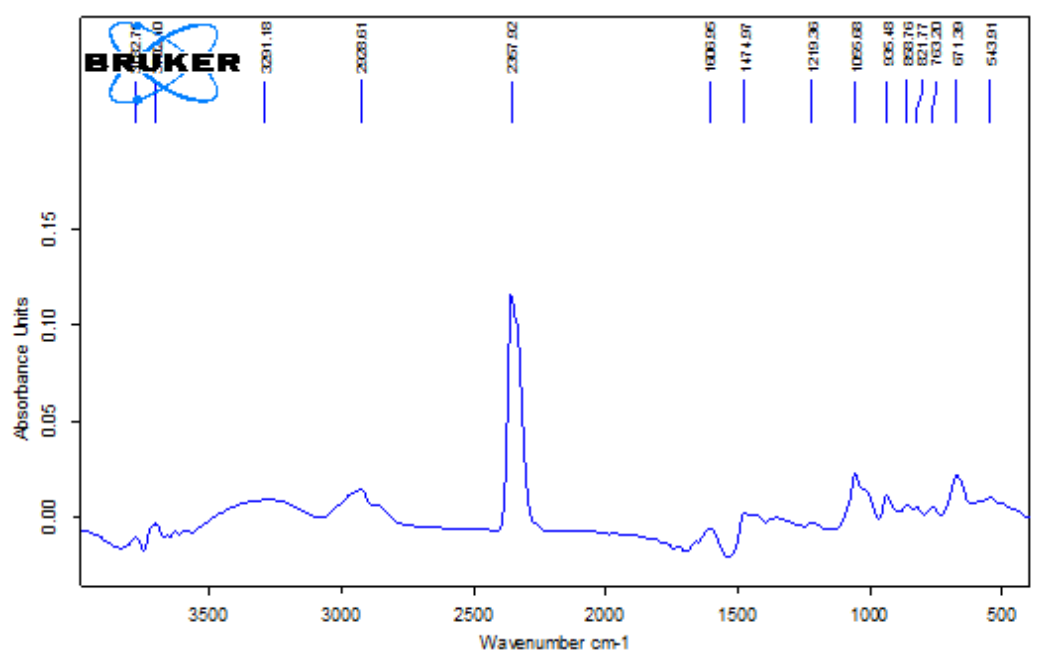

Şekil 8. Lewatit MP 600 reçinesinin Cr (VI) giderimi sonrası FT-IR analizi. Figure 8. FT-IR analysis of Lewatit MP 600 resin after $\mathrm{Cr}$ (VI) removal.

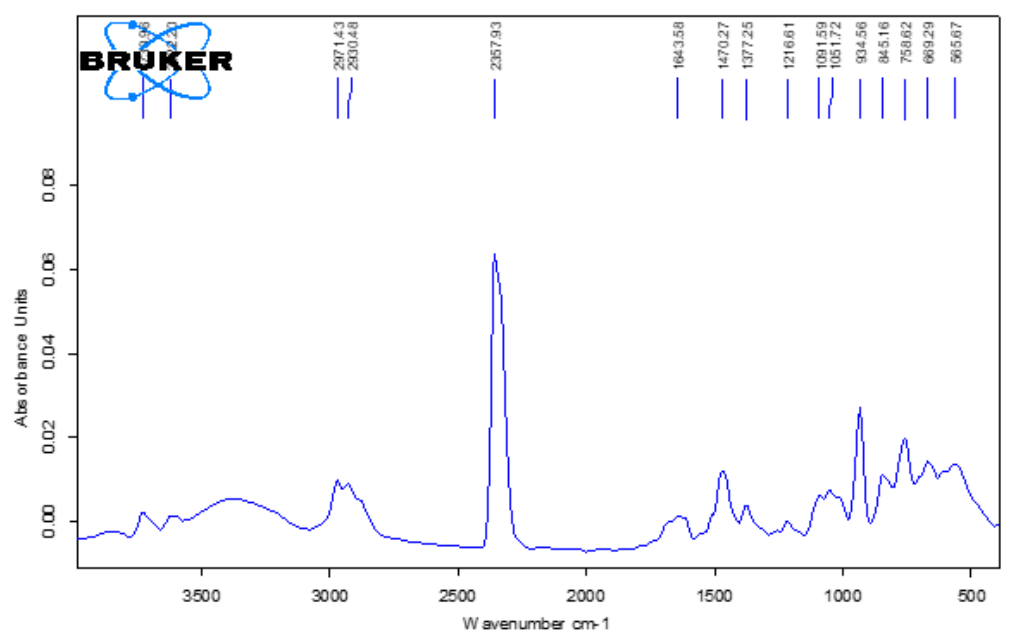

Şekil 9. Lewatit SR 7 reçinesinin Cr (VI) giderimi sonrası FT-IR analizi.

Figure 9. FT-IR analysis of Lewatit SR 7 resin after $C r$ (VI) removal.

Çizelge 3. Lewatit MP 600 ve Lewatit SR 7 reçineleri için Cr (VI) giderimi sonrası piklerdeki değişimler. Table 3. Changes in peaks after $\mathrm{Cr}$ (VI) removal for Lewatit MP 600 and Lewatit SR 7 resins.

\begin{tabular}{|c|c|l|}
\hline $\begin{array}{c}\text { Dalgaboyu, } \\
\mathbf{c m}^{-1}\end{array}$ & Bağ & \multicolumn{1}{c|}{ Açıklama } \\
\hline $3322-3359$ & $\mathrm{O}-\mathrm{H}$ & $\begin{array}{l}\mathrm{Cr}(\mathrm{VI}) \text { giderimi sonrası bantlarda kayma ve pik şiddetinde azalma } \\
\text { gözlenmiştir. }\end{array}$ \\
\hline $2338-2357$ & $\begin{array}{c}\mathrm{C}=\mathrm{C} \\
\mathrm{C}-\mathrm{O}\end{array}$ & $\mathrm{Cr}(\mathrm{VI})$ giderimi sonrası pik şiddetinde artı̧̧ gözlenmiştir. \\
\hline $474-935$ & $\mathrm{C}-\mathrm{H}$ & $\mathrm{Cr}(\mathrm{VI})$ giderimi sonrası ortaya çıkmıştır. \\
& $\mathrm{C}-\mathrm{C}$ & \\
\hline
\end{tabular}

Şekil 8 ve Şekil 9'da verilen FT-IR görüntüleri Şekil 6 ve Şekil 7 ile kıyaslanarak Çizelge 3'de özetlenmiştir. Lewatit MP 600 reçinesi ile Cr (VI) giderimi sonrası 3322-3359 $\mathrm{cm}^{-1}$ 'deki OH- gruplarını işaret eden bantta kayma ve pik şiddetinde azalma gözlenirken $2338-2357 \mathrm{~cm}^{-1}$ bandında pik şiddetinde artış gözlenmiştir. 474-935 $\mathrm{cm}^{-1}$ aralığında görülen $\mathrm{C}-\mathrm{H}$ ve $\mathrm{C}-\mathrm{C}$ bağlarına ait pikler, iyon değiştirici reçinelerin $\mathrm{Cr}(\mathrm{VI})^{\prime} \mathrm{y}$ t tutmasından sonra meydana gelmiştir. 
İyon-Değiştirme Çalışmaları İçin Yapılan Deneyler (Experiments for Ion-Exchange Studies)

İyon değişimi deneylerinde kullanılacak $\mathrm{Cr}$ (VI) stok çözeltisi $\mathrm{K}_{2} \mathrm{Cr}_{2} \mathrm{O}_{7}$ ile hazırlanmıştır. Farklı konsantrasyonlarda $\mathrm{Cr}$ (VI) standart çözeltileri hazırlanarak $375 \mathrm{~nm}$ dalga boyunda UV-Visible spektrofotometresi (Shimadzu UV-1700) ile absorbans değerleri okunmuştur. Elde edilen bu veriler ile standart çözelti konsantrasyonlarının kalibrasyon eğrisi çizilmiş ve kalibrasyon denklemi oluşturulmuştur.

\section{Lewatit MP 600 Reçinesi Kullanılarak Cr (VI) Giderimi (Cr (VI) Removal Using Lewatit MP 600 Resin)}

Bu çalışmada, kuvvetli anyon değiştirici reçineler kullanılarak atık sulardan $\mathrm{Cr}$ (VI) giderimi çalışmaları tamamlanmıştır. $\mathrm{Cr}(\mathrm{VI})$ giderimi üzerinde $\mathrm{pH}$, başlangıç $\mathrm{Cr}(\mathrm{VI})$ konsantrasyonu, temas süresi ve reçine miktarı gibi denge sürecine etki eden parametreler değiştirilerek deneyler gerçekleştirilmiştir. Çizelge 4'de incelenen parametreler ve deney şartları verilmiştir. Vorteks oluşturmadan etkili karıştırma işlemi yapabilmek için numuneler 325 rpm'de çalkalanmıştır. Çalkalama işleminden sonra UV-Visible spektrofotometresi Cr (VI) için son konsantrasyon değerleri ölçülmüştür.

Çizelge 4. Cr (VI) giderimi için incelenen parametreler ve deney şartları. Table 4. Investigated parameters and test conditions for $\mathrm{Cr}(\mathrm{VI})$ removal.

\begin{tabular}{|c|c|c|c|}
\hline \multicolumn{4}{|c|}{ Cr (VI) çözeltileri } \\
\hline $\mathrm{pH}$ & Başlangıç Cr (VI) konsantrasyonu & Temas süresi & Reçine miktarı \\
\hline $100 \mathrm{ppm}$ ve $25 \mathrm{ml}$ & $25 \mathrm{ml}, \mathrm{pH} 2,5-3$ & $25 \mathrm{ml}, \mathrm{pH} 2,5-3,100 \mathrm{ppm}$ & $25 \mathrm{ml}, \mathrm{pH} 2,5-3,100 \mathrm{ppm}$ \\
\hline $1,5-2-3-4-5-6-7$ ve 8 & $\begin{array}{l}10-25-50-100-150-200-250-300- \\
350-400-450 \text { ve } 500 \mathrm{ppm}\end{array}$ & $\begin{array}{c}15-30-40-50-60-90-120-150 \\
\text { ve } 180 \mathrm{dk}\end{array}$ & $\begin{array}{c}0,01-0,015-0,02-0,03-0,04 \\
\text { ve } 0,05 \mathrm{~g}\end{array}$ \\
\hline 0,05 g Lewatit MP 600 reçinesi & 0,05 g Lewatit MP 600 & 0,05 g Lewatit MP 600 reçinesi & Lewatit MP 600 reçinesi \\
\hline \multicolumn{4}{|c|}{$180 \mathrm{dk}, 325 \mathrm{rpm}, 25^{\circ} \mathrm{C}^{\prime}$ de çalkalama } \\
\hline \multicolumn{4}{|c|}{ Dengeye erişim sağlandiktan sonra UV-Visible spektrofotometresinde $\mathrm{Cr}(\mathrm{VI})(375 \mathrm{~nm})$ tayini } \\
\hline
\end{tabular}

\section{a) $\mathrm{pH}^{\prime}$ in $\mathrm{Cr}$ (VI) giderimine etkisi (Effect of $\mathrm{pH}$ on removal of $\mathrm{Cr}$ (VI))}

İyon değiştirme işleminde önemli kontrol parametrelerden biri pH değeridir. Ortam pH'ı birkaç sebepten ötürü iyon değiştiricinin tutma kapasitesini etkileyebilir. Hidrojen ve hidroksil iyonları kuvvetli bir şekilde adsorplandıkları için çözeltinin $\mathrm{pH}^{\prime} ı$ diğer iyonların tutulmasını etkiler. Ayrıca tutma işlemini asidik veya bazik bileşiklerin iyonizasyon derecesini de etkiler. Genellikle belirli bir değere kadar pH azaldıkça iyon tutma kapasitesi artar (Treybal, 1980).

İlk olarak optimum $\mathrm{pH}$ ve temas süresinin iyon değiştirici üzerine etkisini araştırmak için belirli konsantrasyon ve hacimde hazırlanan $\mathrm{Cr}$ (VI) numuneleri için belirli $\mathrm{pH}^{\prime}$ larda denge çalışma deneyleri gerçekleştirilmiştir. 0,1 M NaOH ve 0,1 M HCl çözeltileri ile $\mathrm{Cr}$ (VI) çözelti numuneleri $\mathrm{pH}$ 1,5-8 aralığında 8 farklı $\mathrm{pH}$ değeri ayarlanarak hazırlanmıştır. Kuvvetli anyonik reçine olan Lewatit MP 600'den 0,05 g tartılıp pH'ları ayarlanan her bir çözeltiye eşit olacak şekilde eklenmiştir. Dengeye erişimde farklı pH' daki tüm çözelti numunelerinde, kalan $\mathrm{Cr}$ (VI) konsantrasyonları tespit edilerek ve başlangıç konsantrasyon değeri göz önünde tutularak $\mathrm{Cr}(\mathrm{VI})$ için giderim yüzdelerinin en fazla olduğu $\mathrm{pH}$ değerleri bulunmuştur.

b) Başlangıç konsantrasyonunun Cr (VI) giderimi üzerindeki etkisi (Effect of initial concentration on removal of $\mathrm{Cr}(\mathrm{VI}))$

Lewatit MP 600 iyon değiştirici reçinesi için optimum pH değerleri bulunduktan sonra en uygun başlangıç $\mathrm{Cr}$ (VI) konsantrasyonlarını belirlemek için Cr (VI) stok çözeltisinden 10-500 ppm aralığında 12 farklı konsantrasyon değerinde çözeltiler hazırlanmıştır. Her bir numunenin $\mathrm{pH}^{\prime} 1$ optimum $\mathrm{pH}$ değerine 
ayarlanmıştır. Daha sonra, Lewatit MP 600 reçinesinden Cr (VI) numunelerine 0,05 g olacak şekilde her bir numuneye eklenmiştir. Cr (VI) sulu çözeltilerinden hazırlanan numuneler kesikli kap içerisinde dengeye erişilene kadar karıştırma işlemine devam edilmiştir. $\mathrm{Cr}$ (VI) giderimi, başlangıç konsantrasyonun artırılması ile artmıştır ve $400 \mathrm{mg} / \mathrm{L} \mathrm{Cr}(\mathrm{VI})$ konsantrasyondan sonra sabit bir değere ulaşmıştır.

\section{c) Temas süresinin $\mathrm{Cr}$ (VI) giderimi üzerine etkisi (Effect of contact time on removal of $\mathrm{Cr}$ (VI))}

Temas süresi Cr (VI) gideriminde en önemli parametrelerden biridir. İyon değiştiricinin ilk temas anı çok önemlidir ve ilk temas anında $\mathrm{Cr}$ (VI) tutma hızı yüksektir. Etrafını çeviren sıvı filmdeki Cr (VI)'yı çok hızlı bir şekilde tutmaya başlar. İyon değişim hızındaki azalma, temas süresinin ilerlemesiyle doğru orantılıdır. Optimum temas süresi deneysel çalışmalar yapılarak belirlenir (Deler, 2011).

Temas süresinin Cr (VI) giderimi üzerindeki etkisini incelemek amacıyla Cr (VI) için belirlenen optimum $\mathrm{pH}$ ve konsantrasyon değerleri ayarlanarak numuneler hazırlanmıştır. Daha sonra, Lewatit MP 600 reçinesinden $\mathrm{Cr}(\mathrm{VI})$ numunelerine $0,05 \mathrm{~g}$ olacak şekilde her bir numuneye eklenmiştir. Dengeye ulaşım sağlandıktan sonra ölçülen Cr (VI) konsantrasyonu sonuçlarına göre temas süresinin iyon değişim üzerine nasıl bir etki oluşturduğu yorumlanmıştır.

\section{d) Reçine miktarının $\mathrm{Cr}$ (VI) giderimi üzerine etkisi (Effect of resin dose on removal of $\mathrm{Cr}$ (VI))}

Reçine miktarının Cr (VI) giderimi üzerine etkisini incelemek amacıyla Cr (VI) sulu çözelti numuneleri, belirlenen optimum $\mathrm{pH}$ ve konsantrasyonlarda ayarlanarak ve 0,01-0,05 g aralığında reçine eklenerek gerçekleştirilmiştir. Belirlenen optimum temas süresi sonunda dengeye ulaşım sağlandıktan sonra ölçülen $\mathrm{Cr}$ (VI) konsantrasyonu sonuçlarına göre farklı reçine miktarlarının iyon değişimi üzerine nasıl bir etki oluşturduğu yorumlanmıştır.

Lewatit Sybron Ionac SR 7 Reçinesi Kullanılarak Cr (VI) Giderimi (Removal of Cr (VI) Using Lewatit Sybron Ionac SR 7 Resin)

Lewatit Monoplus 600 reçinesi için yapılan analizlerin tümü, kuvvetli bazik iyon değiştirici reçine olan Lewatit Sybron Ionac SR 7 reçinesi ile benzer şekilde gerçekleştirilmiştir. Lewatit Sybron Ionac SR 7 reçinesi ile $\mathrm{Cr}(\mathrm{VI})$ giderimi için optimum $\mathrm{pH}$, temas süresi, başlangıç konsantrasyonu ve reçine miktarları belirlenerek giderim yüzdeleri karşılaştırılmıştır. Tüm analizler sonucunda; kuvvetli anyonik iyon değiştiriciler olan Lewatit MP 600 ve Lewatit Sybron Ionac SR 7 reçinelerinin Cr (VI) giderimi üzerine etki eden parametrelerinin etkisi belirlenmiştir. Araştırma sonuçları ve tartışma bölümünde her iki reçine için ulaşılan bulgular grafikselleştirilerek yorumlanmıştır. 
ARAŞTIRMA SONUÇLARI VE TARTIŞMA (RESEARCH RESULTS AND DISCUSSION)

Lewatit MP 600 ve Lewatit Sybron Ionac SR 7 Reçineleri Kullanarak Cr (VI) Giderimi (Removal of Cr (VI) Using Lewatit MP 600 and Lewatit Sybron Ionac SR 7 Resins)

a) $\mathrm{pH}$

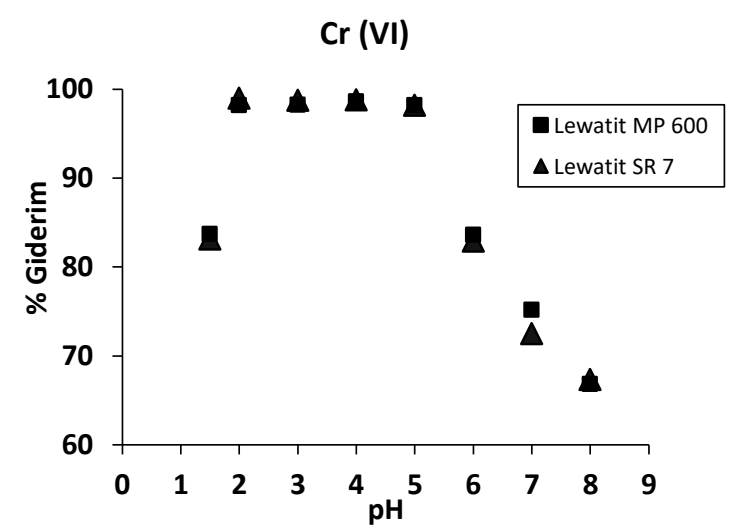

Şekil 10. pH'ın Cr (VI) giderimi üzerindeki etkisi (Giderim şartları: konsantrasyon, 100 ppm; iyon değiştirici dozu, 0,05 g; temas süresi, $180 \mathrm{dk}$; karıştırma hızı, $325 \mathrm{rpm}$; sıcaklık, $25 \pm 1{ }^{\circ} \mathrm{C}$ ).

Figure 10. Effect of $\mathrm{pH}$ on removal of $\mathrm{Cr}$ (VI), (Sorption process; concentration, $100 \mathrm{ppm}$; ion exchanger dose, $0.05 \mathrm{~g}$; contact time, 180 min; mixing speed, $325 \mathrm{rpm}$; temperature $25 \pm 1^{\circ} \mathrm{C}$ ).

Lewatit MP 600 ve Lewatit Sybron Ionac SR 7 anyonik reçineleri ile farklı pH değerlerinde yapılan giderim çalışmalarında $\mathrm{Cr}$ (VI)'nın uzaklaştırılması incelenmiştir. 100 ppm konsantrasyonda $\mathrm{Cr}$ (VI) sulu çözeltilerinden 1,5-8 pH aralığında numuneler hazırlanarak belirlenen temas süreleri boyunca karıştırıcıya bırakılmıştır. Süre bitiminde ölçülen absorbans değerleri sonucunda; Şekil 10'da Cr (VI) iyonlarının 2'nin altındaki $\mathrm{pH}$ değerlerinde tutulması düşük olduğu, $\mathrm{pH}$ 2-5 aralığında $\mathrm{Cr}$ (VI) gideriminin yüksek olduğu ve yüksek $\mathrm{pH}$ değerlerinde ise giderimin azaldığı görülmüştür. $\mathrm{Cr}(\mathrm{VI})^{\prime}$ nın pH 2-5 aralığında çalışılması daha uygun olacağı sonucuna ulaşılmıştır. Düşük pH değerlerinde reçine yüzeyi hidrojen iyonlarıyla kaplanarak pozitif yüklü hale gelmektedir. Ortamda bulunan Cr (VI) iyonları ile reçine yüzeyi arasında elektrostatik etkileşim, hidrofobik etkileşim ve hidrojen bağlarının oluşmasıyla $\mathrm{Cr}$ (VI) reçine tarafından tutulur. $\mathrm{pH}$ 5'den sonraki değerlerde ortamda hidroksil iyonlarının artmasıyla reçine yüzeyi pozitif yüklü hale gelemez. Bu durumda, reçine-krom arasındaki elektrostatik etkileşim, düşük pH'lara göre daha az gerçekleşir. Kullanılan reçineler kuvvetli iyon değiştirici yapılı oldukları için çok güçlü olmayan bazik ortamlarda $(\mathrm{pH} 8)$ bile kromu az da olsa tutabilirler. 
b) Başlangıç Cr (VI) konsantrasyonu (Initial Cr (VI) concentration)

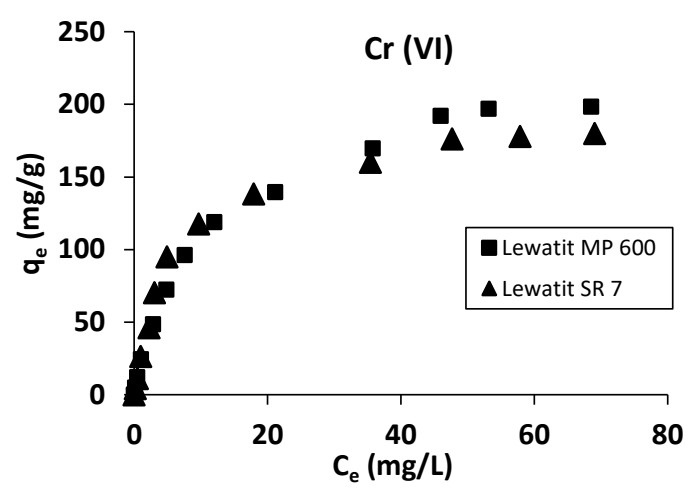

Şekil 11. Başlangıç konsantrasyonunun $\mathrm{Cr}(\mathrm{VI})$ giderimi üzerindeki etkisi (Giderim şartları: $\mathrm{pH}, 2$,5-3; iyon değiştirici miktarı, 0,05 g; temas süresi, $180 \mathrm{dk}$; karıştırma hızı, $325 \mathrm{rpm}$; sıcaklık, $25 \pm 1{ }^{\circ} \mathrm{C}$ ).

Figure 11. Effect of initial concentration on removal of $\mathrm{Cr}$ (VI), (Sorption process; $\mathrm{pH} 2.5-3$; ion exchanger dose, $0.05 \mathrm{~g}$; contact time, 180 min; mixing speed, $325 \mathrm{rpm}$; temperature $25 \pm 1^{\circ} \mathrm{C}$ ).

Cr (VI) stok çözeltisinden farklı konsantrasyonlarda hazırlanılan çözeltiler ile Lewatit MP 600 ve Lewatit Sybron Ionac SR 7 reçinesi muamele edilerek denge çalışmaları tamamlanmıştır. Şekil 11'de başlangıç konsantrasyonları değiştirilerek dengeye gelme durumunda çözeltide kalan konsantrasyonlar $\left(\mathrm{C}_{\mathrm{e}}\right)$ ve iyon değiştiricinin birim kütlesi başına tutulan $\mathrm{Cr}(\mathrm{VI})$ miktarları $\left(\mathrm{q}_{\mathrm{e}}\right)$ değişim grafiği verilmiştir. 10, 25, 50, 100, 150, 200, 250, 300, 350, 400, 450 ve 500 ppm Cr (VI) çözeltileri bir önceki deneyde belirlenen optimum pH 2,5-3 aralığında ayarlanmıştır. Belirlen temas süreleri sonunda ölçülen absorbans

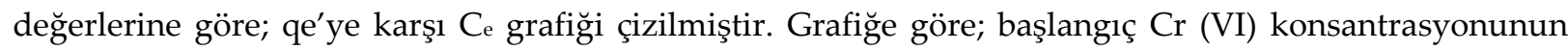
artmasıyla $\mathrm{Cr}$ (VI) gideriminde önce hızlı bir artış görülmekte ve daha sonra sabit değerlere (plato çizgisi) ulaşılmıştır. Her iki reçine için başlangıç $\mathrm{Cr}$ (VI) derişimi yaklaşık $100 \mathrm{mg} / \mathrm{L}$ 'nin üzerine çıkarıldığı zaman dengeye ulaşılmıştır. $\mathrm{Cr}$ (VI) derişiminin bu değerin üzerine çıkarılması $\mathrm{Cr}$ (VI) giderimini değiştirmeyecektir. Bu durum, mevcut reçine yüzeyinin aktif fonksiyonel bölgelerinin dolmasıyla daha fazla kromat anyonlarının reçinelerin yapısına difüzyon edemeyeceğini gösterir.

c) Temas süresi (Contact time)

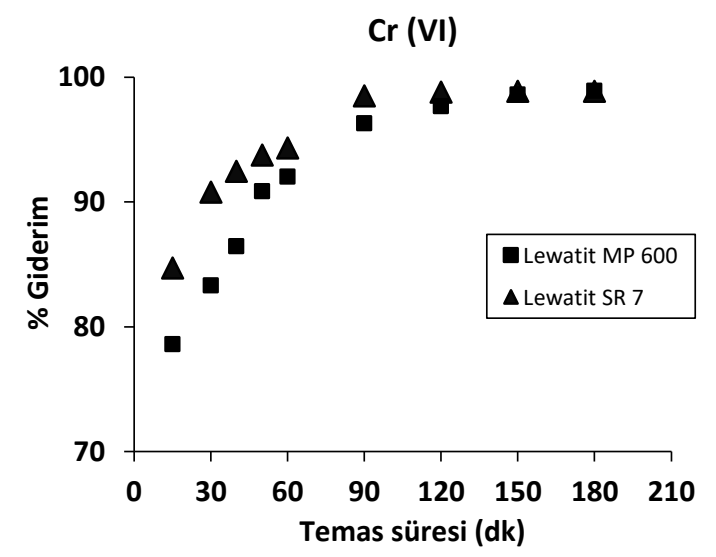

Şekil 12. Temas süresinin $\mathrm{Cr}(\mathrm{VI})$ giderimi üzerindeki etkisi (Giderim şartları: $\mathrm{pH}, 2,5-3$; konsantrasyon, $100 \mathrm{ppm}$; iyon değiştirici miktarı, 0,05 g; karıştırma hızı, $325 \mathrm{rpm}$; sıcaklık, $25 \pm 1{ }^{\circ} \mathrm{C}$ ).

Figure 12. Effect of contact time on removal of $\mathrm{Cr}(\mathrm{VI})$, (Sorption process; $\mathrm{pH} 2.5-3$; concentration, $100 \mathrm{ppm}$; ion exchanger dose, $0.05 \mathrm{~g}$; mixing speed, $325 \mathrm{rpm}$; temperature $25 \pm 1^{\circ} \mathrm{C}$ ). 
Lewatit MP 600 ve Lewatit Sybron Ionac SR 7 ticari reçinelerinin Cr (VI) iyonları giderimine temas süresinin etkisini incelemek amacıyla farklı temas sürelerinde bir dizi iyon değişim deneyleri yapılmıştır. Şekil 12'de temas sürelerine karşı Cr (VI) giderim değişimleri gösterilmiştir. 100 ppm Cr (VI) sulu çözeltileri pH'ları 2,5-3 aralığında olacak şekilde hazırlanmıştır. Belirlenen zaman aralıklarında absorbans değerleri ölçülmüsştür. Cr (VI) uzaklaştırılmada kullanılan iyon değiştiricilerin, $\mathrm{Cr}$ (VI) tutma kapasiteleri belirli bir süre içinde bir plato değerine kadar artmış, plato değeri olan $90 \mathrm{dk}$ 'dan sonra zaman geçtikçe $\mathrm{Cr}$ (VI) tutma yavaşlayarak sabitlendiği gözlemlenmiştir. Her iki iyon değiştiricinin $\mathrm{Cr}$ (VI) iyonları için yapılan çalışmalarda dengeye ulaşma süresi $90 \mathrm{dk}$ olarak belirlenmiştir. Şekil 12 incelendiğinde, $\mathrm{Cr}$ (VI)'nın giderilmesi esnasında, $\mathrm{Cr}(\mathrm{VI})$ iyonlarının reçine yüzeyini homojen bir şekilde kapladığ yüzeyinin $\mathrm{Cr}(\mathrm{VI})$ iyonları ile örtüldüğünü ve tek katmanlı olduğunu görülür.

\section{d) Reçine miktarı (Resin dose)}

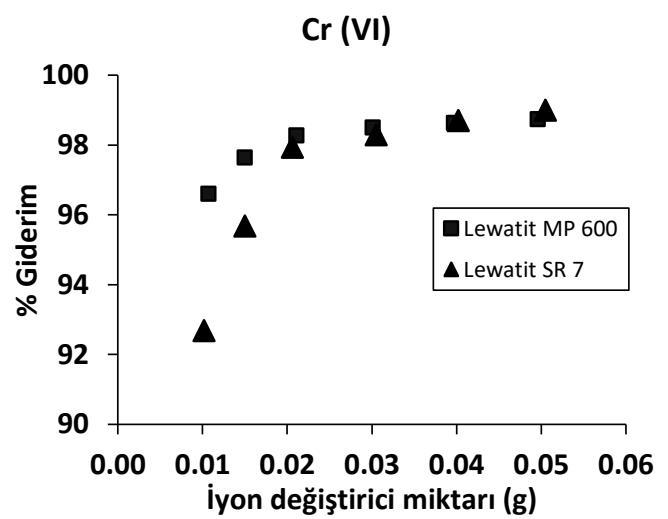

Şekil 13. İyon değiştirici miktarının $\mathrm{Cr}(\mathrm{VI})$ giderimi üzerindeki etkisi (Giderim şartları: $\mathrm{pH}, 2,5-3$; konsantrasyon, 100 ppm; temas süresi, $180 \mathrm{dk}$; karıştırma hızı, $325 \mathrm{rpm}$; sıcaklık, $25 \pm 1{ }^{\circ} \mathrm{C}$ ).

Figure 13. Effect of ion exchanger dose on removal of $\mathrm{Cr}$ (VI), (Sorption process; $p H$ 2.5-3; concentration, 100 ppm; contact time, 180 min.; mixing speed, 325 rpm; temperature $25 \pm 1^{\circ} \mathrm{C}$ ).

Lewatit MP 600 ve Lewatit Sybron Ionac SR 7 anyonik reçinelerinin farklı miktarlarının Cr (VI) giderimi üzerindeki etkilerini incelemek amacıyla, hazırlanan $\mathrm{Cr}$ (VI) sulu çözelti numunelerine farklı miktarlarda reçineler eklenmiştir. Dengeye ulaşım sağlandıktan sonra ölçülen absorbans değerleri sonucunda; Şekil 13'de belirtildiği üzere her iki reçine için $0,02 \mathrm{~g}$ reçine eklenmesi optimum giderim yüzdesine ulaşılması için yeterli olmuştur. 0,05 g'dan daha fazla reçine eklenmesinin giderim üzerinde herhangi bir etkisi olmadığı söylenebilir. Yapılan diğer deneylerde reçine miktarı 0,05 g alınmıştır. Bu durum reçine yüzeyinde bulunan, $\mathrm{Cr}(\mathrm{VI})^{\prime} \mathrm{y} ı$ tutan aktif fonksiyonel grupların doygunluğa ulaştığını gösterir.

\section{Adsorpsiyon Kinetiği (Adsorption Kinetics)}

İyon değişim kinetiği, iyon değiştiricinin $\mathrm{Cr}$ (VI) tutma dinamiğinin daha iyi anlaşılması için önemlidir. Bu nedenle, kinetik parametreler, tutma sürecinin tasarımında ve modellemesinde önemli bir rol oynar ve beklenen model olarak tutma işlemi sırasında tutulan moleküllerin sayısı hakkında bazı bilgiler sağlar (Rafati ve ark., 2016). Reçinelerin Cr (VI)'yı tutma reaksiyonlarında dengeye ulaşıncaya kadar geçen süre, giderim etkinliğini tanımlayan önemli karakteristik özelliklerden biridir (Gode ve Pehlivan, 2005). İyon değiştirme prosesinin mekanizmasını kontrol etmek amacıyla Lewatit MP 600 ve Lewatit Sybron Ionac SR 7 reçinelerinin Cr (VI) giderimi için yalanci-birinci-derece ve yalancı-ikinciderece reaksiyon kinetik değerlerini içeren grafikler Şekil 14 ve Şekil 15'de verilmiştir. 

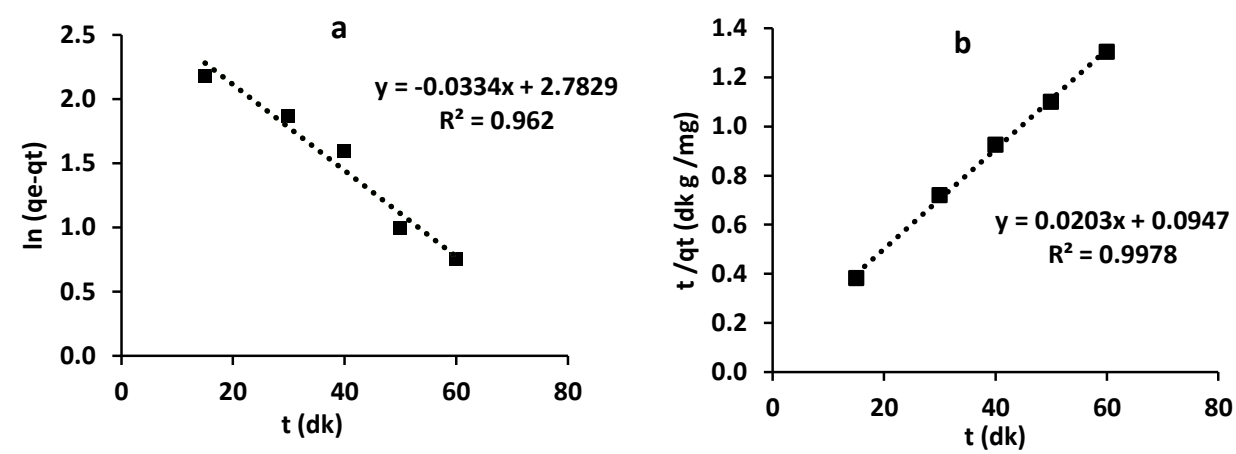

Şekil 14. Lewatit MP 600 reçinesi üzerine $\mathrm{Cr}$ (VI) adsorpsiyon sonuçları a) Yalancı-birinci-derece kinetik model b) Yalanc1-ikinci-derece kinetik modeli (Cr (VI) için; $\mathrm{C}_{0}=100 \mathrm{mg} / \mathrm{L}$, reçine miktarı: 0,05 g, pH:2,5-

3).

Figure 14. Conformity of $\mathrm{Cr}(\mathrm{VI})$ removal results with Lewatit MP 600 resin to kinetic models a) $\mathrm{Cr}$ (VI) pseudo-first-order kinetic model b) $\mathrm{Cr}$ (VI) pseudo-second-order kinetic model (For $\mathrm{Cr}(\mathrm{VI}) ; \mathrm{C}_{0}=100 \mathrm{mg} / \mathrm{L}$, resin amount: 0,05 g, pH:2.5-3).
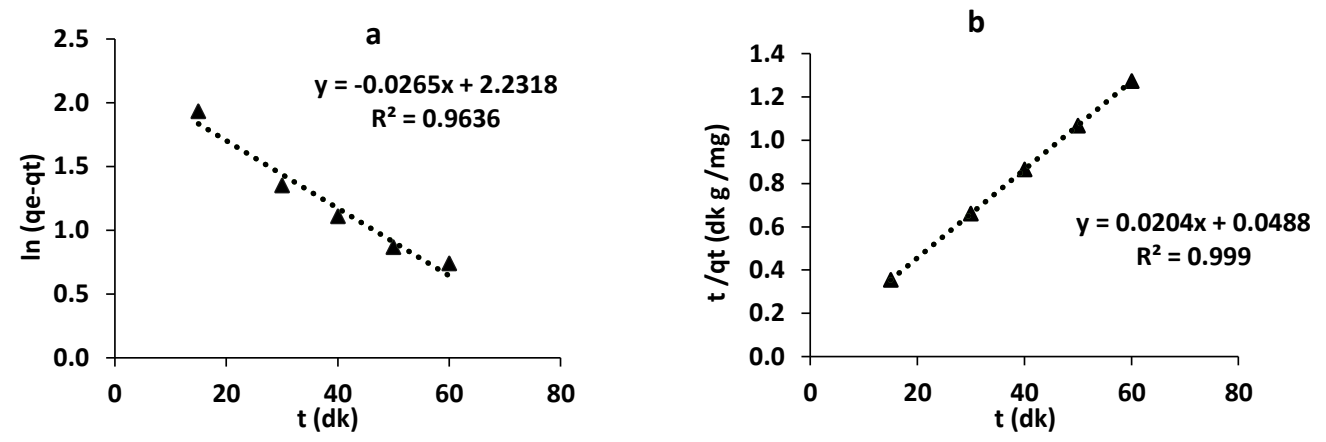

Şekil 15. Lewatit Sybron Ionac SR 7 reçinesi ile Cr (VI) giderimi sonuçlarının kinetik modellere uygunluğu a) $\mathrm{Cr}$ (VI) yalanc1-birinci-derece kinetik model b) $\mathrm{Cr}$ (VI) yalanc1-ikinci-derece kinetik model. ( $\mathrm{Cr}$ (VI) için; $\mathrm{C}_{0}=100 \mathrm{mg} / \mathrm{L}$, reçine miktarı: 0,05 g, pH:2,5-3).

Figure 15. Conformity of $\mathrm{Cr}(V I)$ removal results with Lewatit Sybron Ionac SR 7 resin to kinetic models a) $\mathrm{Cr}$ (VI) pseudo-first-order kinetic model b) $\mathrm{Cr}$ (VI) pseudo-second-order kinetic model (For $\mathrm{Cr}(\mathrm{VI}) ; \mathrm{C}_{0}=100 \mathrm{mg} / \mathrm{L}$, resin amount: 0,05 g, pH:2.5-3).

Çizelge 5. Adsorpsiyon kinetik parametreleri.

Table 5. Adsorption kinetics parametres.

\begin{tabular}{lccccccccl}
\hline & & \multicolumn{4}{c}{ 1. Derece Kinetik } & \multicolumn{2}{c}{ 2. Derece Kinetik } & \\
\cline { 5 - 9 } Anyon & $C_{0}$ & $q_{e_{\text {dny }}}$ & $q_{\boldsymbol{e}_{h s p}}$ & $k_{1}$ & $\mathrm{R}^{2}$ & $q_{\boldsymbol{e}_{\text {hsp }}}$ & $k_{2}$ & $\mathrm{R}^{2}$ & \\
\hline Cr(VI) & 100 & 48,14 & 16,10 & 0,033 & 0,962 & 49,20 & 0,0043 & 0,998 & Lewatit MP 600 \\
Cr(VI) & 100 & 49,22 & 9,31 & 0,027 & 0,964 & 49,00 & 0,0085 & 0,999 & Lewatit SR 7 \\
\hline
\end{tabular}

Kinetik çalışmalar için 100 ppm Cr (VI) çözeltileri hazırlandı. 0,05 g reçine eklenerek çalkalayıcıya konuldu. Belirlenen zaman aralıklarında, çözelti içerisinde kalan $\mathrm{Cr}$ (VI) konsantrasyon tayini yapıldı. Bunun için UV-Visible spektrofotometresi kullanıldı. Ölçümler; $375 \mathrm{~nm}$ dalga boyunda yapıldı.

Çizelge 5 incelendiğinde, deneysel olarak bulunan qe değerleri ile hesaplanan qe değerlerinin yakınlığı göz önüne alındığında, her iki iyon değiştiricinin yalancı-ikinci-derece kinetik modele daha uygun olduğu gözükmektedir. Aynı zamanda korelasyon katsayıları $\left(R^{2}\right)$ incelendiğinde kullanılan iyon değiştiricilerin yalanc1-ikinci-derece kinetik modele daha yakın olduğu görülmektedir. Bu durum, kullanılan iyon değiştiriciler tarafından Cr (VI) iyonlarının giderildiğini ve bu, elektro-statik etkileşime bağlı olarak iyon değişimi şeklinde olan kimyasal bir aktivasyodur (Karakaş, 2019). Cr (VI)'nın giderimi için yalancı-ikinciderece kinetik modelin daha uyumlu olduğu sonucunda varılmıştır. 


\section{Adsorpsiyon İzotermleri (Adsorption Isoterms)}

Adsorpsiyon izotermi, Cr (VI) giderimi tasarımında önemli faktörlerden biridir. Adsorpsiyon izotermi, teorik olarak iyon değiştirme ve $\mathrm{Cr}$ (VI) etkileşiminin nasıl olduğunu açıklar. Bu nedenle, iyon değiştirici kapasitesinin belirlenmesinde ve iyon değiştirici kullanımının optimize edilmesinde ana faktör olarak kabul edilir (Rafati ve ark., 2016). İzoterm verilerinin analizi, tasarım amaciyla kullanılan ve sonuçları doğru şekilde temsil eden bir denklem geliştirmek için önemlidir. Freundlich, Langmuir, Scatchard ve Dubinin-Radushkevic izotermleri genellikle deneysel izotermleri temsil eder (Yasmine ve ark., 2012).

$\mathrm{Cr}$ (VI) giderimi için farklı başlangıç konsantrasyonları alınarak kesikli kap çalışmalarında, reçinelerin Cr (VI)'yı tutma kapasiteleri hesaplanmıştır (Çizelge 6).

Çizelge 6. Adsorpsiyon izotermleri.

Table 6. Adsorption isoterms.

\begin{tabular}{|c|c|c|c|c|c|c|c|c|c|c|c|c|c|}
\hline \multirow[b]{2}{*}{ Anyon } & \multicolumn{3}{|c|}{ Langmuir İzotermi } & \multicolumn{3}{|c|}{ Freundlich İzotermi } & \multicolumn{3}{|c|}{ D-R İzotermi } & \multicolumn{3}{|c|}{ Scatchard İzotermi } & \multirow[b]{2}{*}{ Reçine } \\
\hline & $q_{m}$ & $K_{L}$ & $R^{2}$ & $K_{F}$ & $n$ & $R^{2}$ & $\mathrm{~K}$ & E & $R^{2}$ & $Q_{s}$ & $K_{s}$ & $R^{2}$ & \\
\hline $\mathrm{Cr}(\mathrm{VI})$ & 227,3 & 0,101 & 0,995 & 21,09 & 1,65 & 0,964 & 0,158 & 1,78 & 0,743 & 212,0 & 0,121 & 0,950 & Lewatit MP 600 \\
\hline $\mathrm{Cr}(\mathrm{VI})$ & 200,0 & 0,145 & 0,999 & 22,66 & 1,72 & 0,910 & 0,162 & 1,76 & 0,776 & 203,8 & 0,140 & 0,940 & Lewatit SR 7 \\
\hline
\end{tabular}

Dengeye ulaşıldığında, Lewatit MP 600 ve Lewatit SR 7 reçinesi gram miktarları için tutulan Cr (VI) ve çözelti ortamında tutunmadan kalan $\mathrm{Cr}$ (VI) konsantrasyonlarının Freundlich, Langmuir, Scarthard ve D-R adsorpsiyon izotermlerine uyumluluğu incelenmiştir.

Deneysel verilerin Freundlich izotermine uygunluğunu belirlemek amaciyla Freundlich denkleminden $K_{F}$ ve $n$ değerleri hesaplanarak Çizelge 6'da verilmiştir. n değerleri Lewatit MP 600 reçinesiyle giderilen Cr (VI) için 1,65 ve Lewatit SR 7 reçinesi ile giderilen Cr (VI) için ise 1,72 olarak bulunmuştur. Bu değerlerin 1-10 aralığında olması iyon değişiminin uygun olduğunu göstermektedir. Dubinin-Radushkevich izotermi için D-R denklemi kullanılarak, E ve K sabit değerleri hesaplanmıştır. Adsorpsiyon enerjisi (Ead) değeri Lewatit MP 600 reçinesi için 1,78 kj/mol ve Lewatit SR 7 reçinesi için 1,76 kj/mol olarak bulunmuştur. Ortalama adsorpsiyon enerjisi değerinin $8 \mathrm{kj} / \mathrm{mol}$ 'den düşük olması Cr (VI) gideriminin iyon değişimi ile gerçekleştiğini kuvvetlendirir. Scatchard izoterminin uygunluğunu tespit etmek için $Q_{s}$ ve $K_{s}$ sabit değerleri hesaplanmıştır. Bu izotermde MP 600 iyon değiştiricisi için maksimum kapasite (Qs) 212,1 mg/g ve R² değeri 0,950 bulunmuştur. SR 7 iyon değiştiricisi için Qs değeri 203,8 mg/g ve $\mathrm{R}^{2}$ değeri 0,940 olarak bulunmuştur. Bu değerler Langmuir izoterminin uygunluğunu destekler niteliktedir. Scatchard analizi adsorpsiyon prosesinin Langmuir veya Freundlich izotermlerine uygunluğu hakkında yorum yapabilmeyi sağlayan bir grafiktir. Scatchard analizlerinde grafiğin doğrusallığa yaklaşması Langmuir izotermine yaklaştığını gösterir. Bu durum, adsorpsiyonun tek tabakalı adsorpsiyona daha yakın olduğuna işaret eder (Parlayıcı, 2016). Kullanılan iyon değiştiriciler için hesaplanan kapasite verilerine ve korelasyon katsayılarına bakıldığında Langmuir izoterminin diğer izotermlere göre daha uygun olduğu görülmektedir. Langmuir izotermine göre Lewatit MP 600 iyon değiştiricisi için 227,3 mg/g ve Lewatit Sybron Ionac SR 7 iyon değiştiricisi için ise 200,0 mg/g Cr (VI) giderim kapasitesi hesaplanmıştır.

Langmuir izotermine uygun olması; iyon değiştirici yüzeyinin kapasite bakımından homejen ve yüzey üzerinde aktif merkezler bulunduğunu gösterir. Her bir aktif merkeze bir anyonik grup bağlanır. Bu anyonik moleküller arasında herhangi bir etkileşim yoktur ve enerjileri tüm merkezlerde aynıdır (Tahir ve ark., 2016). Bu nedenle kullanılan iyon değiştirici mükemmel düz ve homejen bir yüzeye sahip olarak kabul edilir. Tutulan moleküllerinin oluşturdukları tabaka adsorban yüzeyinde tek tabaka halinde ve hareketsizdir. 


\section{Reçine Rejenerasyonu (Resin Regeneration)}

Reçinelerin yeniden kullanılabilirliğini araştırmak için desorpsiyon deneyleri yapılmıştır. Belirli bir çözünen madde için (kromat anyonu) adsorpsiyon aşamasının sonunda, çözelti ortamından ayrılan reçine numunesi ultra saf su ile birkaç kere yıkanmıştır. Reçineler, desorpsiyon çalışması için $1 \mathrm{~mol} / \mathrm{L} \mathrm{NaOH}$ çözeltisi ile bir gün boyunca muamele edilmiştir. Çözeltiler süzülerek, reçineler bazik çözeltiden ayrılmıştır. Daha sonra reçineler ultra saf su ile yıkanmıştır. Kurutulan reçineler iyon değişimi işlemi için başlangıç materyali olarak yeniden kullanılmıştır. Şekil 16'da reçineler için yüzde Cr (VI) giderimleri verilmiştir. Reçinelerin üç kez rejenerasyonu sonunda giderim çok az değişmiş olup reçinelerin tekrar kullanılabileceği sonucuna varılmıştır.

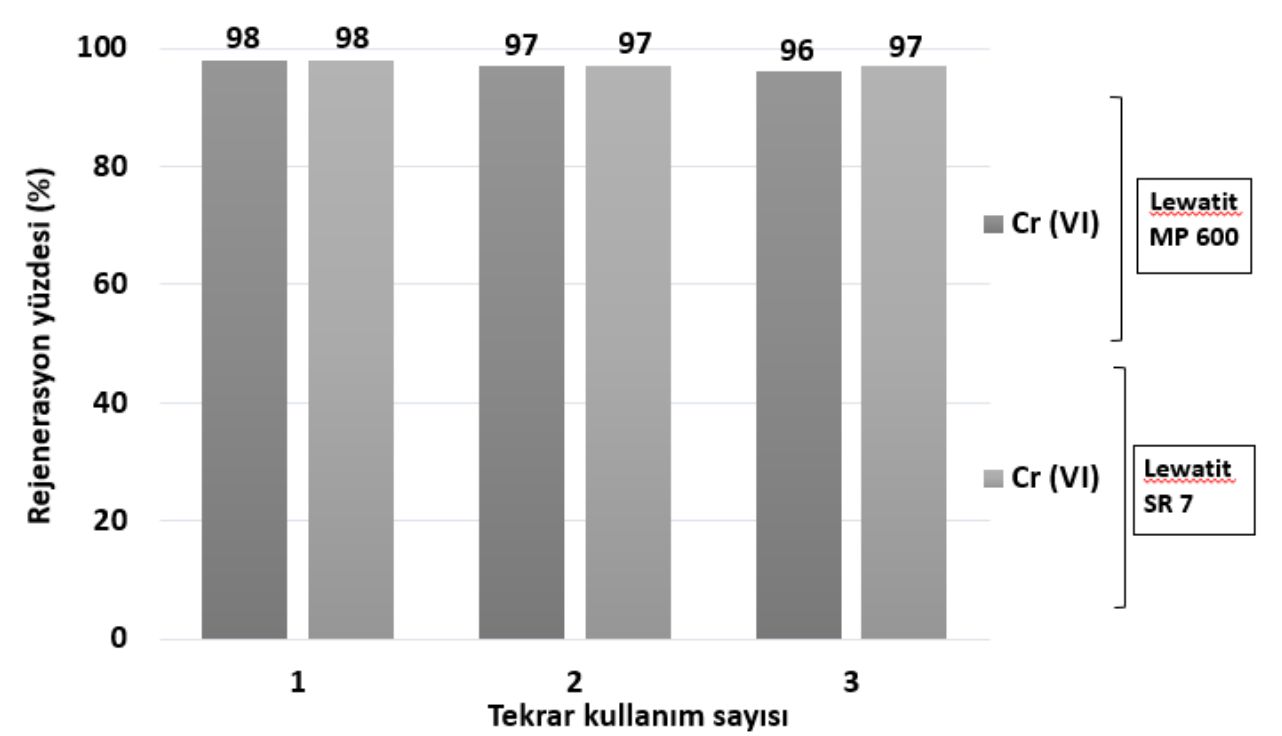

Şekil 16. Reçine rejenerasyonu.

Figure 16. Resin regeneration.

\section{SONUÇLAR (CONCLUSIONS)}

Bu çalışmada, Lewatit MP 600 ve Lewatit Sybron Ionac SR 7 iyon değiştiricileri kullanılarak Cr (VI)'nın sulu çözeltilerden giderimi tamamlanmıştır. Bu reçineler, $\mathrm{Cr}$ (VI)'nın sudan uzaklaştırılması için ideal bir tutucudur. Denge çalışmalarında temas süresi, başlangıç $\mathrm{Cr}$ (VI) konsantrasyonu, $\mathrm{pH}$ ve reçine miktarı gibi belirli deneysel parametreler denenmiştir. $\mathrm{Cr}$ (VI) sulu çözeltisi için optimum pH 2-5 aralığ1 belirlenmiştir. İyon değişim çalışmalarında kullanılan iyon değiştirici miktarları her iki reçine için $0,05 \mathrm{~g}$ olarak belirlenmiştir. Dengeye ulaşma süresi $90 \mathrm{dk}$ olarak belirlenmiştir. Kısa sürede dengeye ulaşılarak hızlı krom giderimi, reçinelerin Cr (VI)'yı tutma etkinliğinin yüksek olduğunu göstermiştir. Cr (VI) giderim miktarının bulunması, diğer bir ifade ile reçinelerin kapasite tayini, $\mathrm{Cr}$ (VI) konsantrasyonları değiştirilerek çizilen adsorpsiyon izotermlerine, izoterm modelleri (Langmuir, Freundlich, D-R, Scatchard) uygulanarak yapılmıştır. Her iki reçine için de Langmuir izoterm modelinin Cr (VI) giderimi için daha uygun olduğu sonucuna varılmıştır. Bu izoterme göre, Lewatit MP 600 ve Lewatit Sybron Ionac SR 7 iyon değiştiricilerinin maksimum Cr (VI) tutma kapasitesi, sırası ile 227,3 mg/g ve 200,0 mg/g olarak bulunmuştur. Her iki reçine için yalancı-ikinci-derece kinetik model daha uygun olmuştur. Sonuç olarak, yapılan deneylerden bu iyon değiştirici reçinelerinin atık sudan $\mathrm{Cr}(\mathrm{VI})$ 'nın uzaklaştırılması için dikkate değer reçineler olduğu görülür ve arıtma tesislerinde kullanılması önerilir. 


\section{TEŞEKKÜR (ACKNOWLEDGMENT)}

Bu çalışma, Selçuk Üniversitesi Bilimsel Araştırma Projeleri (BAP) birimi tarafından 211016001 nolu proje ile desteklenmiştir.

\section{KAYNAKLAR (REFERENCES)}

Adam, M. R., Salleh, N. M., Othman, M. H. D., Matsuura, T., Ali, M. H., Puteh, M. H., Ismail, A., Rahman, M. A. ve Jaafar, J., 2018, The adsorptive removal of chromium (VI) in aqueous solution by novel natural zeolite based hollow fibre ceramic membrane, Journal of environmental management, 224, 252-262.

Ali, S. W., Mirza, M. L. ve Bhatti, T. M., 2015, Removal of Cr (VI) using iron nanoparticles supported on porous cation-exchange resin, Hydrometallurgy, 157, 82-89.

Ashbolt, N. J., 2004, Microbial contamination of drinking water and disease outcomes in developing regions, Toxicology, 198(1-3), 229-238.

Balan, C., Volf, I. ve Bilba, D., 2013, Chromium (VI) removal from aqueous solutions by purolite base anion-exchange resins with gel structure, Chemical Industry and Chemical Engineering Quarterly/CICEQ, 19 (4), 615-628.

Bonilla-Petriciolet, A., Mendoza-Castillo, D. I. ve Reynel-Ávila, H. E., 2017, Adsorption processes for water treatment and purification, Springer, $p$.

Deler, Ö., 2011, Perlit Kullanılarak Pentakloranitrobenzen Adsorpsiyonu, Yüksek Lisans Tezi, Yıldız Teknik Üniversitesi, İstanbul.

Economou-Eliopoulos, M., Antivachi, D., Vasilatos, C. ve Megremi, I., 2012, Evaluation of the Cr (VI) and other toxic element contamination and their potential sources: The case of the Thiva basin (Greece), Geoscience Frontiers, 3 (4), 523-539.

Gandhi, M. R., Viswanathan, N. ve Meenakshi, S., 2010, Adsorption mechanism of hexavalent chromium removal using Amberlite IRA 743 resin, Ion Exchange Letters, 3, 25-35.

Gode, F. ve Pehlivan, E., 2005, Removal of Cr (VI) from aqueous solution by two Lewatit- anion exchange resins, Journal of Hazardous Materials, B119, 175-182.

Kahraman T. H. ve Pehlivan E., 2019, Evaluation of anion-exchange resins on the removal of $\mathrm{Cr}(\mathrm{VI})$ polluted water: batch ion-exchange modeling, Arabian Journal of Geosciences, 12:532.

Karakaş, M., 2019, Sulu Çözeltilerden Adsorpsiyon Yöntemi İle Cr (VI) Giderimi, Yüksek Lisans Tezi, Sakarya Üniversitesi, Fen Bilimleri Enstitüsü, Sakarya.

Karakurt, S., 2019, Removal of Carcinogenic Arsenic from Drinking Water By the Application of Ion Exchange Resins, Oncogen Journal, 2 (1), 5.

Mohan, D., Rajput, S., Singh, V. K., Steele, P. H. ve Pittman Jr, C. U., 2011, Modeling and evaluation of chromium remediation from water using low cost bio-char, a green adsorbent, Journal of Hazardous Materials, 188 (1-3), 319-333.

Ngah, W. W., \& Fatinathan, S. (2008). Adsorption of Cu (II) ions in aqueous solution using chitosan beads, chitosan-GLA beads and chitosan-alginate beads. Chemical Engineering Journal, 143(1-3), 62-72.

Parlayıcı, Ş., 2016, Bazı Ağır Metal İyonlarının Uzaklaştırılmasında Kullanılacak Yeni Tabii ve Sentetik Kompozit Adsorbanların Geliştirilmesi, Doktora Tezi, Selçuk Üniversitesi, Fen Bilimleri Enstitüsü, Konya.

Parlayıc1, Ş. ve Pehlivan E., 2017, Adsorption of Cr(VI) from the aqueous solution by apricot stones activated carbon, International Proceedings of Chemical, Biological and Environmental Engineering, V01. 10120.

Parlayıcı, Ş. ve Pehlivan, E., 2020, Biosorption of methylene blue and malachite green on biodegradable magnetic Cortaderia selloana flower spikes: modeling and equilibrium study, International Journal of Phytoremediation, 1-15.

Pradhan, D., Sukla, L. B., Sawyer, M. ve Rahman, P. K., 2017, Recent bioreduction of hexavalent chromium inwastewater treatment, Journal of Industrial and Engineering Chemistry, 1-20. 
Rafati, L., Ehrampoush, M. H., Rafati, A. A., Mokhtari, M. ve Mahvi, A. H., 2016, Modeling of adsorption kinetic and equilibrium isotherms of naproxen onto functionalized nano-clay composite adsorbent, Journal of Molecular Liquids, 224, 832-841.

Rashid, J., Barakat, M. ve Alghamdi, M., 2014b, Adsorption of chromium (VI) from wastewater by anion exchange Resin, J. of Advanced Catalysis Science and Technology, 1 (2), 26-34.

Suganya, S., 2018, Influence of ultrasonic waves on preparation of active carbon from coffee waste for the reclamation of effluents containing Cr (VI) ions, Journal of Industrial and Engineering Chemistry, 60, 418-430.

Tahir, M. A., Bhatti, H. N. ve Iqbal, M., 2016, Solar Red and Brittle Blue direct dyes adsorption onto Eucalyptus angophoroides bark: Equilibrium, kinetics and thermodynamic studies, Journal of Environmental Chemical Engineering, 4 (2), 2431-2439.

Treybal, R. E., 1980, Mass transfer operations, New York, 466.

Vedula, S. S., \& Yadav, G. D., 2021, Wastewater treatment containing methylene blue dye as pollutant using adsorption by chitosan lignin membrane: Development of membrane, characterization and kinetics of adsorption. Journal of the Indian Chemical Society, 100263.

Yasmine, A. O., Malika, C., Abdeltif, A. ve Aicha, B., 2012, Sorption of hexavalent chromium metal onto Amberlite IRA 410-equilibrium isotherms and kinetic studies, Desalination and Water Treatment, 38 (Desalination and Water Treatment, 38 (1-3), 409-415.

Wawrzkiewicz M., Hubicki Z. and Polska-Adach E., 2018, Strongly basic anion exchanger Lewatit MonoPlus SR-7 for acid, reactive, and direct dyes removal from wastewaters, Separation Science and Technology, 53 (7), 1065-1075. 